\title{
Effect of Polyamide 6 on Crystallization Nucleation Behavior and
}

\section{Mechanical Properties of Polyoxymethylene}

\author{
Chunfa Ouyang ${ }^{1, a^{*}}, X$ Xiang $^{1, b}$, Weili Xue ${ }^{1, c}$, Qun Gao ${ }^{1, d}$, Zhengchuang \\ Zhao $^{1, e}$, Kangsheng Zheng ${ }^{1, f}$, Wang Zhang ${ }^{2, g}$, Duoyou Zhang ${ }^{2, h}$ \\ ${ }^{1}$ School of Materials Science \& Engineering, Shanghai Institute of Technology, Shanghai, 201418, \\ China \\ 2 Shanghai Bluestar POM Ltd. , Shanghai, 201419, China \\ aouyoung_0916@163.com, bxijiyumingxi@163.com, xueweili2@163.com, dwityy@sit.edu.cn, \\ eenhengzzc1003@163.com, ${ }^{\mathrm{f}} 13661499682 @ 163 . c o m,{ }^{9}$ zhangwang@bluestar.chemchina.com, \\ hzhangduoyou_1@163.com
}

Keywords: Polyoxymethylene, Polyamide 6, Crystallization, Nucleating agent, Toughening Abstract.The present study is the first propose use of secondary melt-processing, in which polyamide 6 (PA6) were successfully dispersed in Polyoxymethylene (POM) and POM/PA6 blends were prepared carried with POM. The effect of PA6 on crystallization nucleation behavior and mechanical properties of POM have been studied. PA6 has great heterogeneous nucleation effect and toughening effect on POM due to hydrogen bond interaction in POM/PA6 blends. Scanning electron microscopy analysis(SEM) showed that brittle-ductile transition occurred when PA6 was added in POM.

\section{Introduction}

Polyoxymethylene (POM) is a linear high crystalline polymer with excellent mechanical properties, widely used in machinery, automotive, electrical and electronics, instrumentation applications ${ }^{[1-3]}$. POM possesses good mechanical properties but shows notch sensitive with poor impact strength, high contractibility and low thermo-degradation temperature in melting process, which restrain its applications in many high-tech fields ${ }^{[4,5]}$. To improve its notched impact strength, many efforts have been devoted to toughening $\mathrm{POM}^{[6-8]}$. This article reports the preparation of POM/PA6 blends by secondary melt blending and the mechanical properties and crystalline behavior of POM/PA6 are also studied.

\section{Experimental}

\section{Materials}

The POM (BS090) used in this study is supplied by Bluestar POM Co., Ltd. PA6 is purchased from Guangdong Xinhui Meida Nylon Co., Ltd. and the grade is M2500, which is a homopolymer with melting and crystallization temperatures of $223^{\circ} \mathrm{C}$ and $172^{\circ} \mathrm{C}$.

\section{Preparation of the Modified POM}

POM, PA6 were mixed in a high-speed mixer of weight ratio $7 / 3$, then extruded by a twin-screw extruder at a rotational speed of $30 \mathrm{rpm}$. The temperature of the barrel was in the range of $200-225^{\circ} \mathrm{C}$. Then the extrudates were crushed into fine particles. POM blended with the masterbatch in a certain 
percentage, then extruded by a twin-screw extruder at a rotational speed of $30 \mathrm{rpm}$. The temperature of the barrel was in the range of $160-190^{\circ} \mathrm{C}$.

\section{Fourier Transform Infrared Spectroscopy (FTIR) Analysis}

FTIR analysis of POM/PA6 blends was conducted with Nicolet-380 infrared spectrometer (USA) at 32 scans, and the sample was fabricated by hot pressing.

\section{Polarized Light Microscopy (PLM) Observation}

The crystalline morphologies of virgin POM and POM/PA6 were observed by using Axio Scope.A1 polarized light microscope (PLM) of Carlzeiss, Germany. The samples were heated and melted on a hot plate at $200^{\circ} \mathrm{C}$ between two glass slides and pressed to a flake, then crystallized at $150^{\circ} \mathrm{C}$ for $3 \mathrm{~h}$. The magnification of the microscope is 200 times.

\section{Differential Scanning Calorimeter (DSC) measurements}

The crystallization behavior of samples was examined on a differential scanning calorimeter (DSC Q200, USA, TA). All samples about $10 \mathrm{mg}$ were heated from $25^{\circ} \mathrm{C}$ to $180^{\circ} \mathrm{C}$ with the heating rate of $20^{\circ} \mathrm{C} /$ min under nitrogen atmosphere and kept at this temperature for $5 \mathrm{~min}$ to remove the thermal history. And then the samples were cooled to $120^{\circ} \mathrm{C}$ at the speed of $20^{\circ} \mathrm{C} / \mathrm{min}$ and kept at this temperature for $5 \mathrm{~min}$. Then the temperature was raised to $140^{\circ} \mathrm{C}$ with the heating rate of $20^{\circ} \mathrm{C} / \mathrm{min}$, then raised to $180^{\circ} \mathrm{C}$ at the speed of $2^{\circ} \mathrm{C} / \mathrm{min}$. Finally, the samples was cooled to $120^{\circ} \mathrm{C}$ with cooling rate of $2^{\circ} \mathrm{C} / \mathrm{min}$. The higher the crystallinity $\left(X_{c}\right)$, the more the melting heat. $X_{c}$ can be calculated by the following equation:

$$
X_{c}=\frac{\Delta H_{m}}{\Delta H_{0}} \times 100 \%
$$

where $\Delta H_{m}$ is the melting enthalpy of the samples and $\Delta H_{0}$ is the melting enthalpy of $100 \%$ crystallizing polymer. $\Delta H_{0}$ for POM is equal to $190 \mathrm{~J} / \mathrm{g}$.

\section{Mechanical Property Measurement}

Tensile performance was measured with a SUN-500 (Italy, GALDABINI) material testing machine according to GB/T 1042-92 with a cross-head speed of $50 \mathrm{~mm} / \mathrm{min}$. The impact strength of the samples was measured with charpy impact testing machine(XJU-22J, Jiangdu Jingcheng Test Instrument) according to GB1843-93.

\section{Scanning Electron Microscope (SEM) Observation}

The surface morphology analysis of impact spline brittle fracture in liquid nitrogen was performed with Quanta200 scanning electron microscopy (SEM; FEI, USA). Operating voltage was $200 \mathrm{kV}$.

\section{Results and discussion}

\section{Hydrogen-bond Interaction}

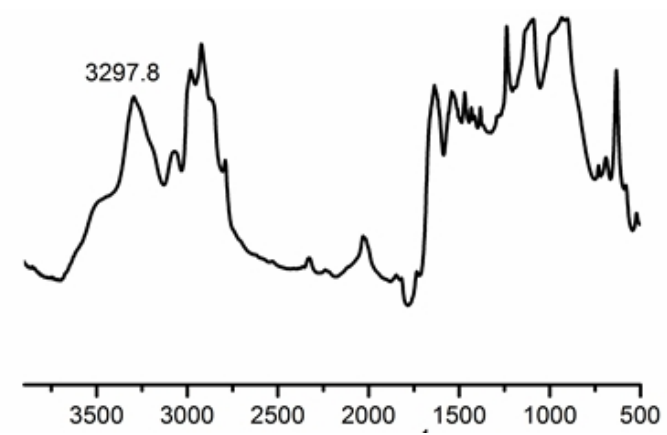

Fig. 1 FTIR spectrum of blend POM/PA6=7/3

In the process of polymer blends, although the structure of polymer bonds is very different, the interaction force (electronic interaction, hydrogen bonding) between the groups provide the 
necessary impetus for increasing the miscibility ${ }^{[9]}$. For POM/PA6 blend, the two components are contained - O-, -NH groups so that the absorption peak in the infrared spectrum of their blend appears at the wave number $3297.8 \mathrm{~cm}^{-1}$ (Fig .1), which is stretching absorption peaks of N-H $\square \mathrm{O}$ hydrogen bonding, indicating the formation of hydrogen bonding interactions during melt blending process $^{[10]}$.

\section{The Nucleation Effect of PA6 on POM}

By the method of secondary melt blending to prepare POM/PA6 blends can solve the problem that PA6 can't be well dispersed in the POM matrix. The heterogeneous nucleation role of nucleating agents initiates more crystal nucleus and more molecular chains align into the lattices, and the PLM images of the nucleated POM were shown in Fig. 2.

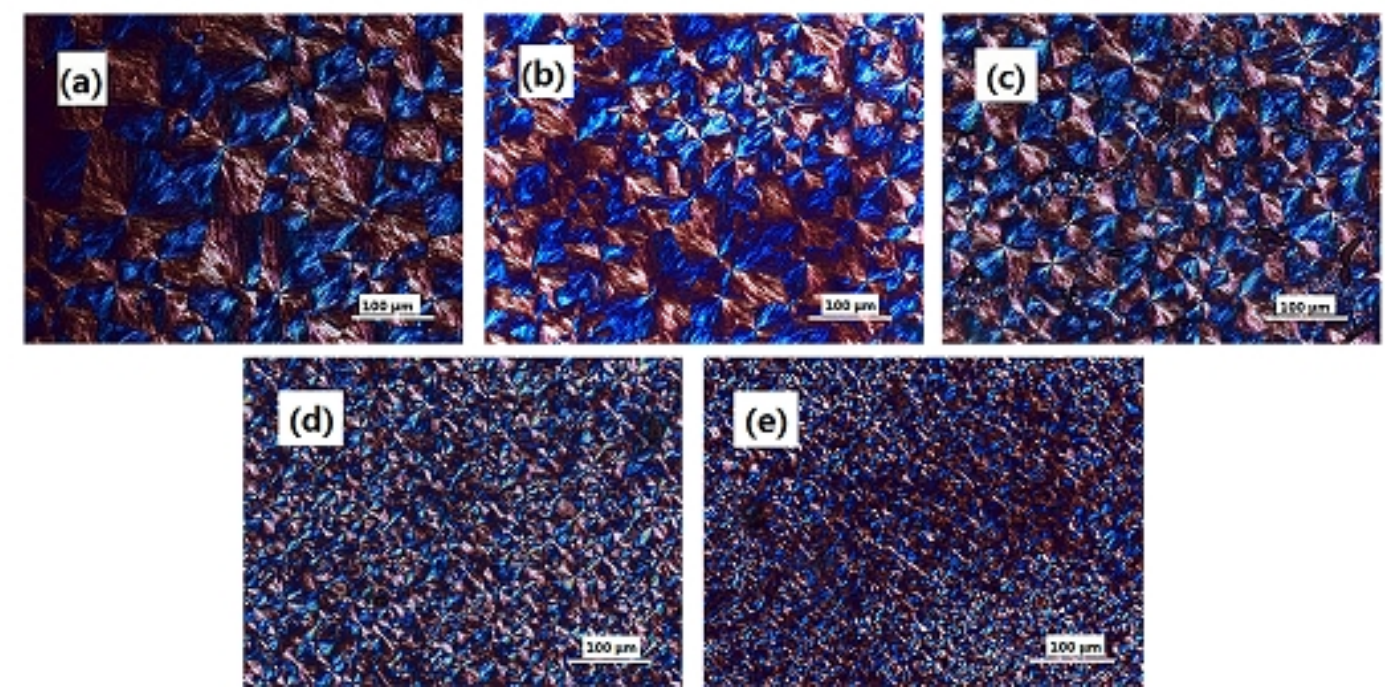

Fig. 2 The PLM images of virgin POM and POM with different contents of PA6, the PA6 content of samples a-e were $0,0.15,0.3,0.6$ and $0.9 \mathrm{wt} \%$, respectively.

In the figure of virgin POM, the obvious Maltese cross patterns were found, which was the characteristics of spherulites, and the spherulite size was large and uneven. However, the spherulites were more perfect and the size became smaller with the increase of PA6 content, meanwhile, the interface between the spherulites was blurred, resulting in the dispersion of internal stress at the interface. The crystallization temperature of PA6 is $172^{\circ} \mathrm{C}$, which is higher than that of $\mathrm{POM}\left(148^{\circ} \mathrm{C}\right)$, so when POM cooled from melt during processing, PA6 dispersed in POM matrix acted as the nucleating agent to provide the molecular chains more crystal nucleus for POM, which reflects the heterogeneous nucleation of PA6 and shows PA6 has good compatibility and dispersity with POM.

\section{Non-isothermal Crystallization of POM}

The non-isothermal DSC curves of POM and POM/PA6 were shown in Fig. 3. The onset crystallization temperature $\left(T_{\text {onset }}\right)$, the crystallization peak temperature $\left(T_{c}\right)$, the melting temperature $\left(T_{m}\right)$, the melting enthalpy $\left(\Delta H_{m}\right)$, the crystallinity $\left(X_{c}\right)$, and the degree of subcooling $(\Delta T)$ can be obtained, as listed in Table 1.

From Fig. 3(a), it can be seen that the onset crystallization slope became steeper and the crystallization peak became more acute upon the addition of PA6. The PA6 caused the crystallization temperature $\left(T_{c}\right)$ of POM to shift to a higher temperature, initial slope of crystallization increased, indicating that PA6 promoted the crystallization of POM.

From Table 1, it can be seen that for POM/PA6, $T_{\text {onset }}, T_{c}$ increased and $\Delta T$ became narrower than the virgin polymer, which further demonstrates the nucleation effect of PA6 on POM, making POM crystallize more quickly at comparatively high temperature. Furthermore, $\Delta H_{m}, X_{c}$ and $\Delta T$ reached a minimum at $0.6 \mathrm{wt} \%$ PA6, subsequently, they began to increase. 

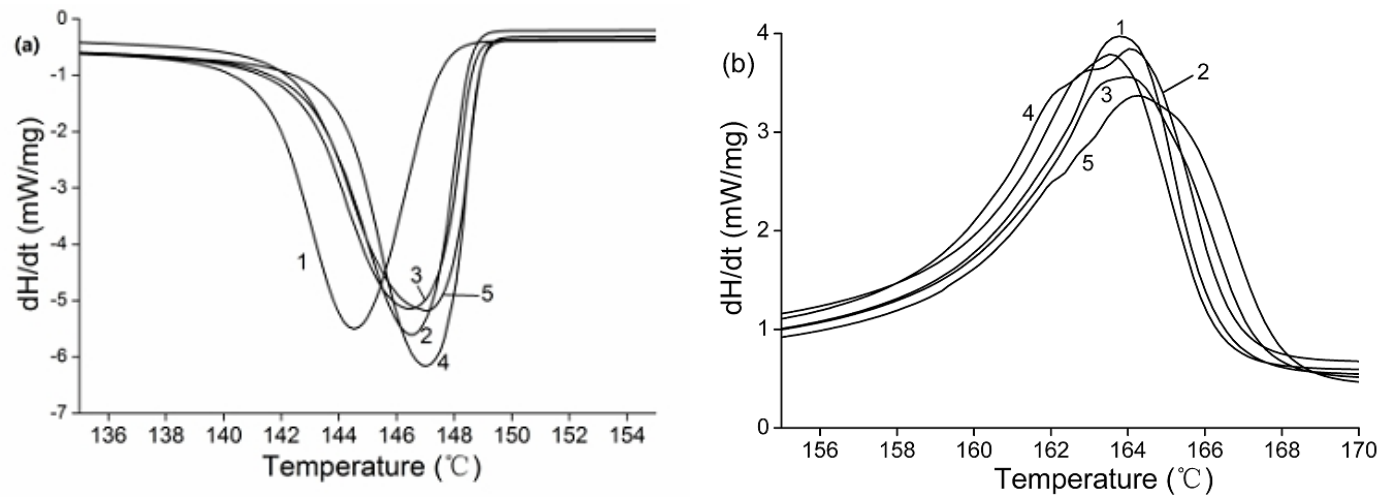

Fig. 3 DSC curves of virgin POM and POM with different contents of PA6 with cooling rate (a) and heating rate (b) of $2^{\circ} \mathrm{C} / \mathrm{min}$. The PA6 content of samples $1-5$ were $0,0.15,0.3,0.6$ and $0.9 \mathrm{wt} \%$, respectively.

Table 1 Non-isothermal Crystallization parameters of virgin POM and POM/ PA6

\begin{tabular}{cccccccc}
\hline Sample & $\begin{array}{c}\text { PA6 content } \\
(\mathrm{wt} \%)\end{array}$ & $\begin{array}{c}T_{\text {onset }} \\
/{ }^{\circ} \mathrm{C}\end{array}$ & $\begin{array}{c}T_{m} \\
/{ }^{\circ} \mathrm{C}\end{array}$ & $\begin{array}{c}\Delta H \\
/ \mathrm{J} / \mathrm{g})\end{array}$ & $\begin{array}{c}X_{c} \\
/ \%\end{array}$ & $\begin{array}{c}T_{c} \\
/{ }^{\circ} \mathrm{C}\end{array}$ & $\begin{array}{c}\Delta T \\
/{ }^{\circ} \mathrm{C}\end{array}$ \\
\hline 1 & 0 & 147.58 & 163.77 & 133.30 & 70.16 & 144.51 & 19.2 \\
2 & 0.15 & 148.60 & 164.03 & 130.84 & 68.86 & 146.44 & 17.5 \\
3 & 0.3 & 148.72 & 163.96 & 124.62 & 65.59 & 146.52 & 17.4 \\
4 & 0.6 & 148.94 & 163.52 & 118.53 & 62.38 & 147.04 & 16.4 \\
5 & 0.9 & 149.00 & 164.28 & 118.68 & 62.46 & 147.05 & $1(01)$ \\
\hline
\end{tabular}

\section{Mechanical Properties}

As shown in Fig. 4, the mechanical properties of POM were improved by the addition of PA6, and reached the maximum at PA6 in the amount of $0.6 \mathrm{wt} \%$. This may be result from the reduction of the spherulites size and stress concentration induced by the heterogeneous nucleation of PA6. Which indicates that the number of nuclei did not increase, the excess of the nucleating agent became crystal defects and resulted in the decrease of mechanical properties ${ }^{[5]}$.
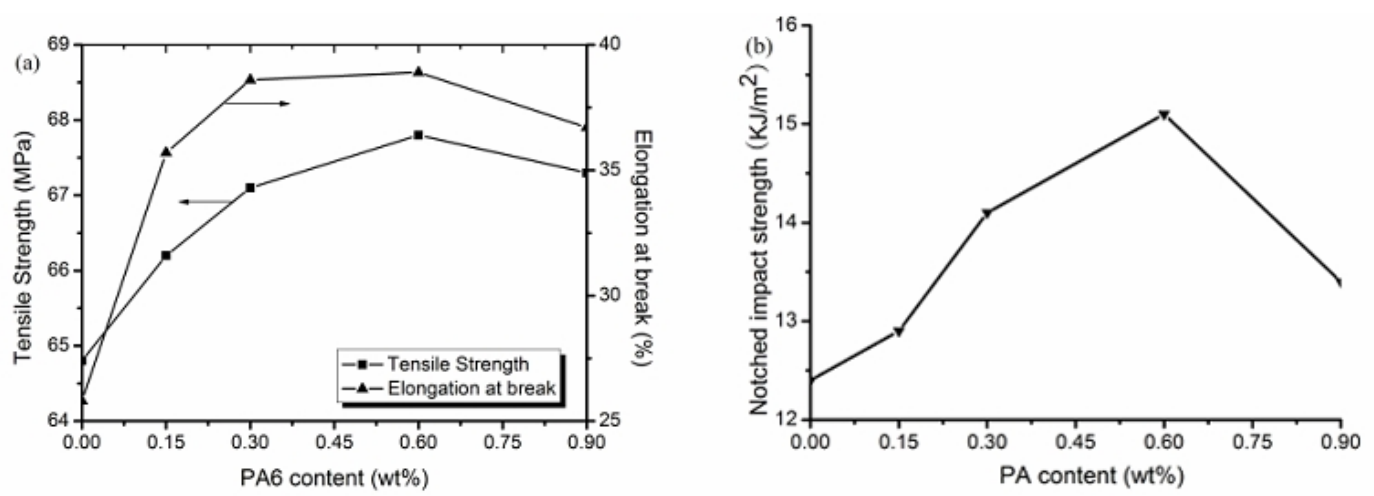

Fig. 4 Effect of PA6 content on the mechanical properties of POM.

Fig. 5 showed the brittle fractured surfaces morphology of virgin POM and POM/PA6 blends observed by SEM. It can be seen that the fractured surface of virgin POM is very distinct, smooth, and shows the brittle fracture mechanism; while the fractured surface of POM/PA6 presents a lot of stress whiteness, cotton and becomes blurred. The brittle-ductile transition occurs, which is coincident with the improvement of the mechanical properties of $\mathrm{POM}^{[6]}$. 

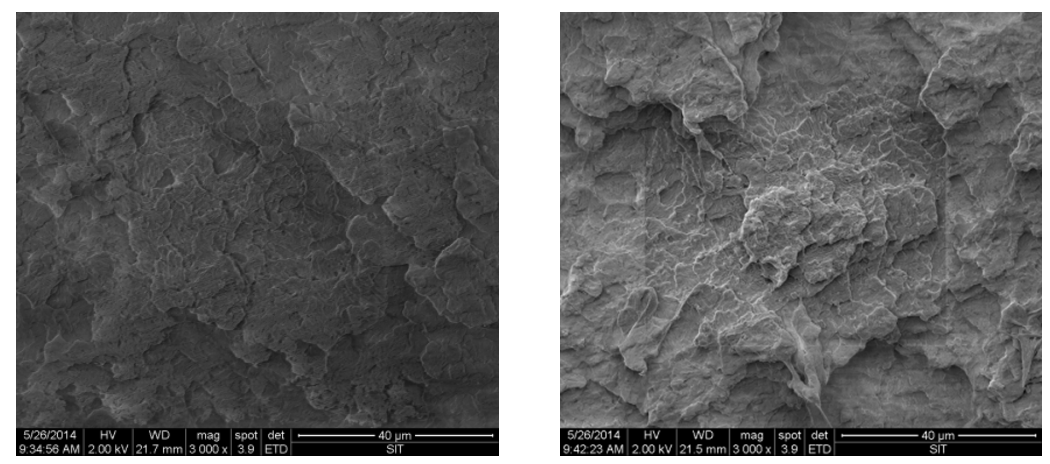

Fig. 5 SEM images of tensile fractured surfaces of POM and POM/PA6

\section{Conclusion}

In this study, POM/PA6 blends were prepared by the method of secondary melt blending, which successfully solve the problem that PA6 can't be dispersed in the POM well. By non-isothermal crystallization and PLM observation can get a conclusion that PA6 as has a significant nucleation effect on POM. The adding of PA6 caused the $T_{m}$ of the POM increased, spherulites refined, the grain size reduced dramatically. The excellent miscibility of POM and PA6 resulted from the interaction of hydrogen bonds, coincident with the improvement in the mechanical properties of POM with the addition of PA6.

\section{Reference}

1. S. Hasegawa, H. Takeshita, F. Yoshii, T. Sasaki, K. Makuuchi, S. Nishimoto. Thermal degradation behavior of gamma-irradiated acetyloxy end-capped poly(oxymethylene), Polym. 2000, 41, 111-120.

2. P. Liu, W. Xu, M. Zhang. Effect of nucleation on the crystallizing and mechanical properties of polyoxymethylene, Polym. Mater. Sci. \& Eng. 2004, 20, 147-150.

3. L.P. Guo, X.M. Xu, Y.D. Zhang, Z.J. Zhang. Effect of Functionalized Nanosilica on Properties of Polyoxymethylene-Matrix Nanocomposites, Polym. Compos. 2014, 35, 127-136.

4. G.M. Whitesides, J.P. Mathias, C.T. Seto. Molecular self-assembly and nanochemistry: a chemical strategy for the synthesis of nanostructures. Sci. 1991, 254, 1312-1319.

5. W.B. Xu, S.W. Zhu, Q.Y. Cai. Study on nucleation of polyamide 12 to polyoxymethylene. Plast. Indust. 2000, 28, 34-36.

6. Y.L. Hu, L. Ye. Nucleation effect of polyamide on polyoxymethylene. Polym. Eng. Sci. 2005, 45, 1174-1179.

7. K. Kawaguchi, K. Mizuguchi, K. Suzuki, H. Sakamoto, T. Oguni. Mechanical and physical characteristics of cellulose-fiber-filled polyacetal composites. Appl. Polym. Sci. 2010, 118, 1910-1920.

8. A.J. Jose, M. Alagar. Development and Characterization of Organoclay-Filled Polyoxymethylene Nanocomposites for High Performance Applications. Polym. Compos. 2011, 32, 1315-1324.

9.X. Li. Study of PVDF / PMB compatibility and the crystalline structure. Polym. Mater. Sci. Eng. 1993, 3, 30-33.

10.W.B. Xu, S.W. Zhu, Q.Y. Cai. Study on microstructure and mechanical properties of POM/COPA blends. Polym. Sci. Eng. 1996, 6, 123-126. 